\title{
“Jogo da Tradução”: uma ferramenta pedagógica no ensino de genética
}

\section{"Translation Game": an educational tool in the genetics of education}

\author{
${ }^{1}$ Carlos Alberto Sanches Pereira sanches68@gmail.com \\ ${ }^{1}$ Ana Paula Cunha Pereira \\ 1 Júlio Cezar Azevedo da Silva Junior \\ ${ }^{1}$ Gabriela Girão de Albuquerque \\ ${ }^{2}$ Valéria da Silva Vieria
}

\section{RESUMO}

As dificuldades no processo de ensino e aprendizagem dos conteúdos de genética é bastante discutida nos meios escolar e acadêmico, principalmente o que tange aos aspectos relacionados às dificuldades de aplicabilidade e abstração dos conceitos que são abordados nesta disciplina. A proposta de uso da informática como ferramenta didática é cada vez mais comum em diversas áreas do saber. Buscando facilitar a compreensão de alguns conteúdos da disciplina de Genética, foi criado um jogo tecnológico onde os alunos pudessem interagir com os constituintes celulares envolvidos nos processos de transcrição de tradução. Dessa forma, o objetivo deste trabalho é apresentar a construção e a forma de uso de um jogo digital de genética intitulado: “Jogo da Tradução”. Através da união de noções básicas em informática com conteúdos teóricos, concretizou-se a criação do "Jogo da Tradução”. Um jogo digital, construído com recursos básicos do PowerPoint, o qual permite o aluno à aplicação do conhecimento teórico para ele mesmo construir sua proteína. Este jogo permite o professor trabalhar de forma lúdica e interativa o conteúdo de genética molecular, um assunto normalmente tratado de forma exclusivamente teórica.

Palavras-chave: Ensino e aprendizagem de genética. Jogo lúdico. Tecnologias no ensino.

\begin{abstract}
The difficulties in teaching and learning process of genetic content is much discussed in school and academic resources, especially with respect to matters relating to the applicability of difficulty and abstraction of the concepts that are discussed in this discipline. The computer usage proposal as a teaching tool is becoming increasingly common in many areas of knowledge. Seeking to facilitate the understanding of some of Genetics discipline of content, a technological game where students could interact with cellular components involved in the translation processes of transcription was created. Thus, the aim of this paper is to present the construction and form of use of a digital genetic game entitled "Translation Game." By combining basics in computer science with theoretical content, materialize the creation of "Translation Game." A digital game, built with basic features of PowerPoint, which allows the student to apply the theoretical knowledge to himself build your protein. This game allows the teacher to work in a fun and interactive way the content of molecular genetics, a subject usually treated only theoretically.
\end{abstract}

1 Centro Universitário de Volta Redonda, Rio de Janeiro - Mestrado Profissional em Ensino em Ciências da Saúde e do Meio Ambiente.

2 Instituto Federal de Ciência e Tecnologia do Rio de Janeiro. 
Keywords: Teaching and learning genetics. Playful game. Technology in education.

\section{INTRODUÇÃO}

Há uma onda consensual na literatura internacional, iniciada na década de 1990, apontando as dificuldades encaradas pelos professores ao ensinar os conceitos biológicos relativos a genética molecular no cotidiano da sala de aula (BUGALLO, 1995; BANET \& AYUSO, 1995; BAHAR et. al., 1999). No ano de 2002, um estudo conduzido na Zâmbia, revelou os vários temas da biologia considerados difíceis quanto ao ato de ensinar e aprender envolvendo professores e alunos (HAAMBOKOMA, et. al., 2002) e dentre estes, o tema da genética foi classificado como um dos mais difíceis.

Com bases nestas pesquisas, observou-se que o uso da tecnologia aliada ao ensino pode contribuir com uma importante estratégia para vislumbrar os complexos processos celulares como a tradução proteica por exemplo (MIRRA, 2018; SAFITRI, et. al., 2017; CHEN, SCOTT, STEVENS, 2017). Uma justificativa plausível para tal uso, reside nas formas diferenciadas de intervenção dos educadores cujo intuito é desenvolver oportunidades de aprendizado. Um exemplo disso, é o uso da web-based, uma ferramenta de simulação que dá suporte aos estudantes no aprendizado de genética, estimulando as habilidades para responder verdadeiro/falso e ainda, o que os pesquisadores chamam de questões de base-compreensão. Após a simulação, compara-se o aprendizado dos estudantes que utilizaram a web-based com o aprendizado oriundo dos livros didáticos (FLEISCHNER, et. al., 2017).

Seguindo esta vertente, elaboramos "O Jogo da Tradução" uma ferramenta didática para o ensino, de forma dinâmica, atendendo as diferentes etapas envolvidas no processo de síntese das proteínas celulares. Para a utilização deste jogo é imprescindível que os alunos retomem alguns conceitos básicos de genética, tais como, a compreensão sobre ácidos nucleicos e os processos de duplicação, transcrição e tradução.

Para um estudante, o processo de construção das proteínas pode ser muito abstrato, por isso, se ele puder apropriar-se de um jogo, ao mesmo tempo unindo o prazer ao aprendizado, as teorias poderão se tornar menos abstratas e mais próximas de sua realidade. Em outras palavras, a proposta de utilização de um jogo na dinâmica da sala de aula, atrela-se a vertente de ensino baseada na contextualização do conhecimento ensino aprendizagem, comumente caracterizado pelo diálogo estabelecido entre os conteúdos escolares e a realidade a qual o aluno vivencia (FESTAS, 2015; MACEDO, SILVA, 2014).

Observando por este ângulo e associando a possibilidade do professor construir por ele próprio seu jogo, o "Jogo da Tradução", foi elaborado com a utilização de recursos básicos do PowerPoint, que estão ao alcance de qualquer pessoa que tenha um domínio mínimo deste software. Dessa forma, o objetivo deste trabalho foi apresentar a construção e a forma de uso de um jogo digital de genética intitulado: “Jogo da Tradução".

\section{PROCEDIMENTOS PARAA CONSTRUÇÃO DO JOGO}

O jogo foi construído a partir de diferentes slides que demonstram os processos metabólicos ocorridos durante a duplicação, transcrição e tradução. Todos os movimentos foram programados utilizando o recurso “TRANSIÇÕES” (Figura 1), onde foi estabelecido um tempo de "DURAÇÃO” para a transição entre os slides. Em cada um deles a molécula que pretendemos movimentar ocupa uma devida posição, dando assim o efeito do movimento. 
Figura 1 - Montagem dos movimentos

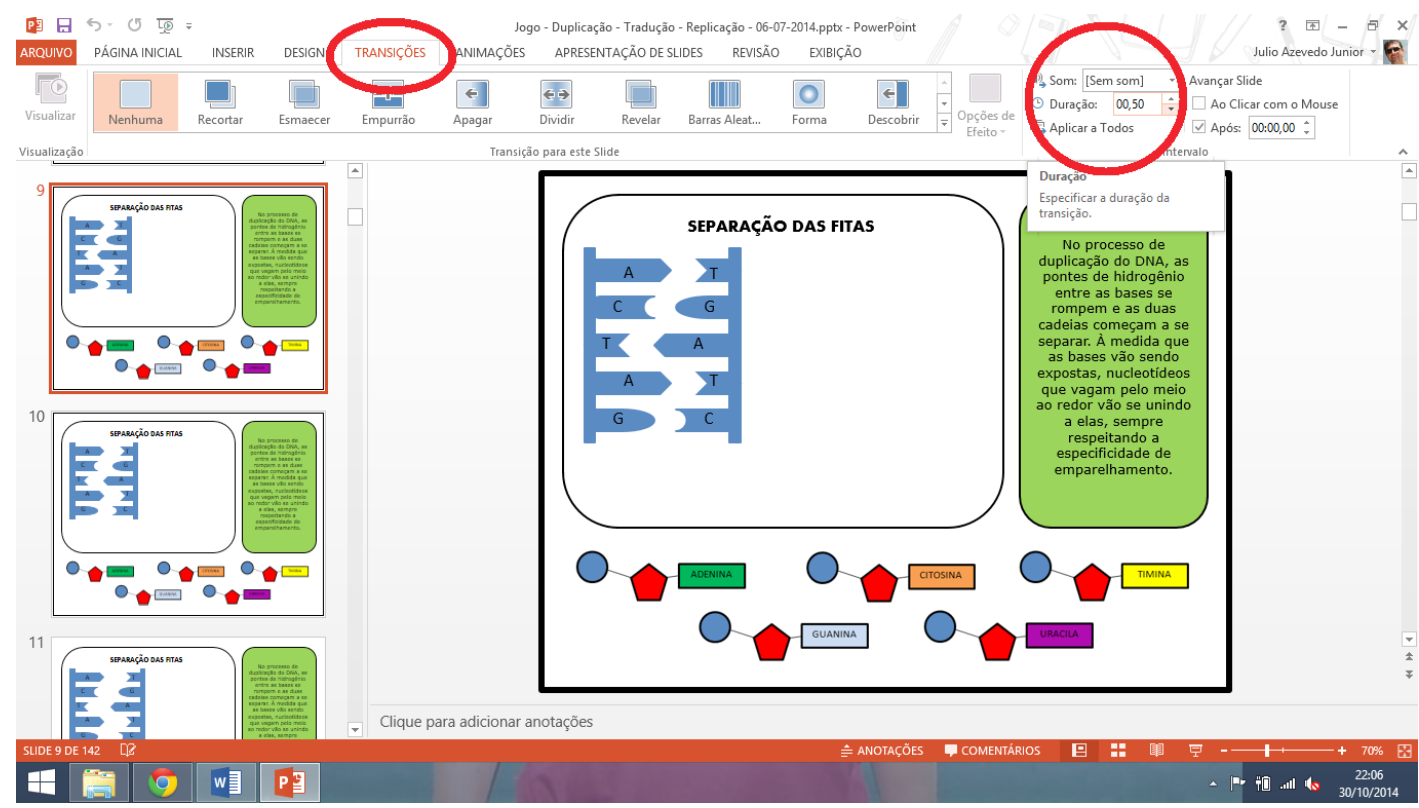

Fonte: ?

Para a adição de uma molécula na cadeia de DNA ou em um RNA mensageiro, com apenas um clique do mouse, utilizamos o recurso de "HIPERLINK" (Figura 2) para estabelecermos as transições corretas entre os slides. Em "HIPERLINK” escolhemos a opção "Colocar neste documento" (Figura 3), em seguida marca-se o slide que se deseja (Figura 4).

Figura 2 - Utilizando o "Hiperlink"

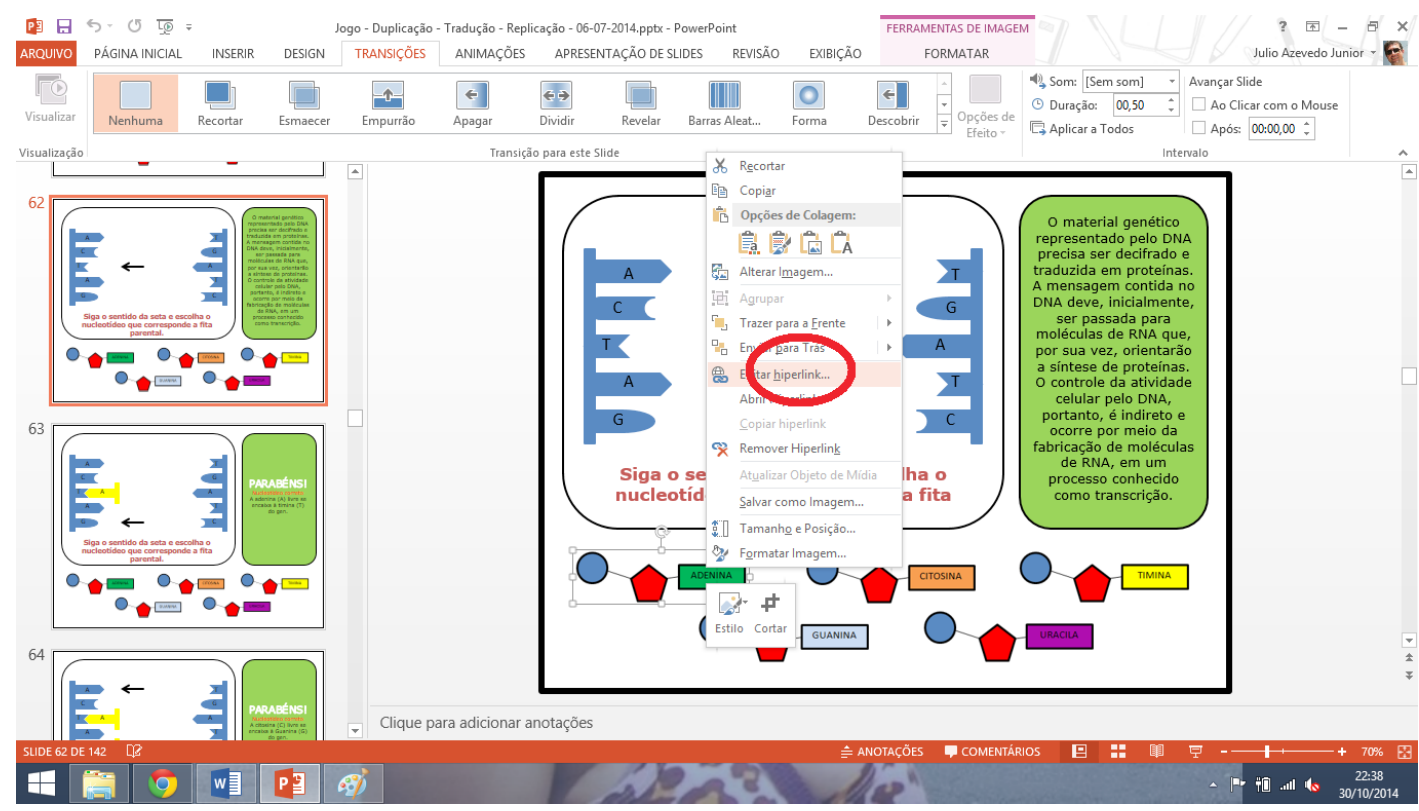

Fonte: ? 
Figura 3 - Escolhendo “Colocar neste documento".

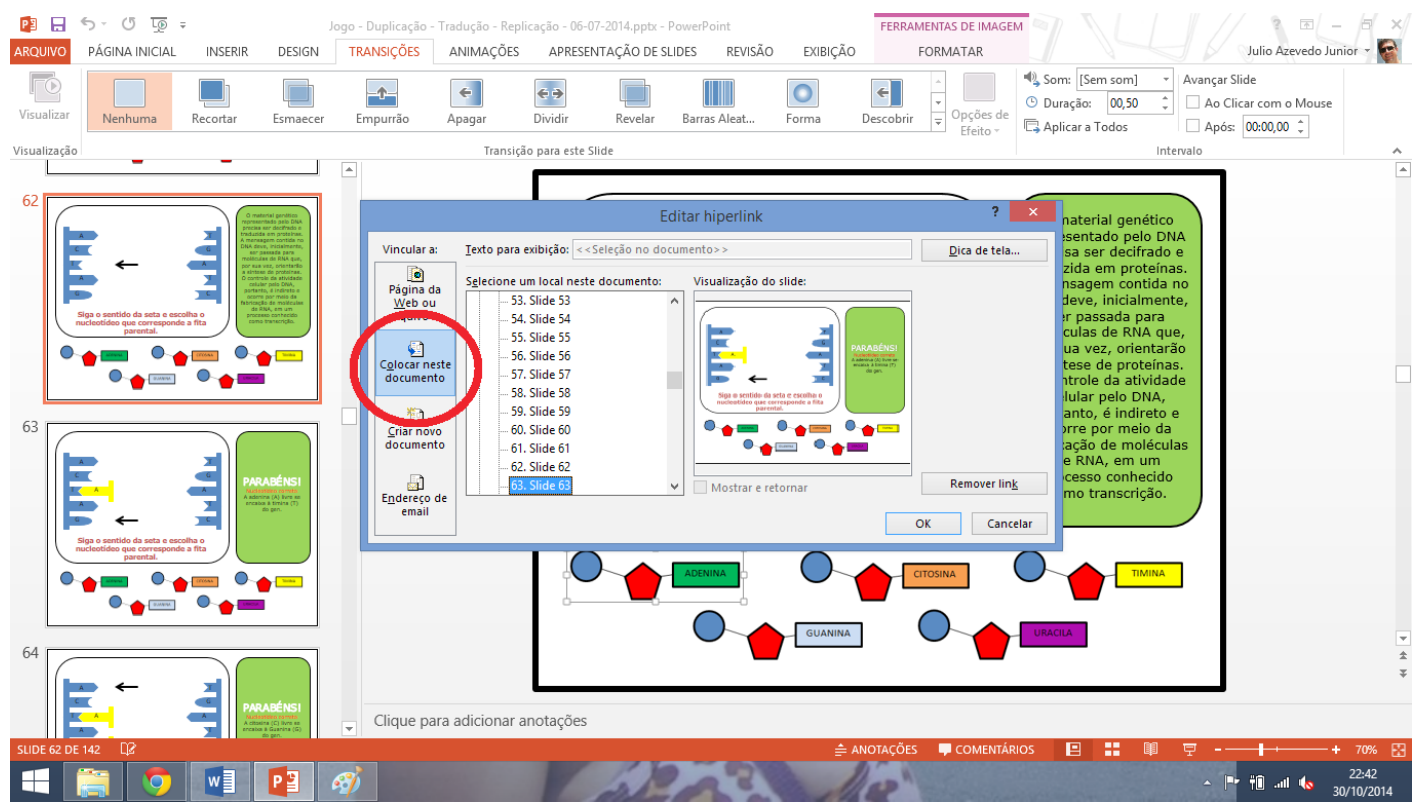

Fonte: ?

Figura 4 - Selecionando o Slide desejado para a transição.

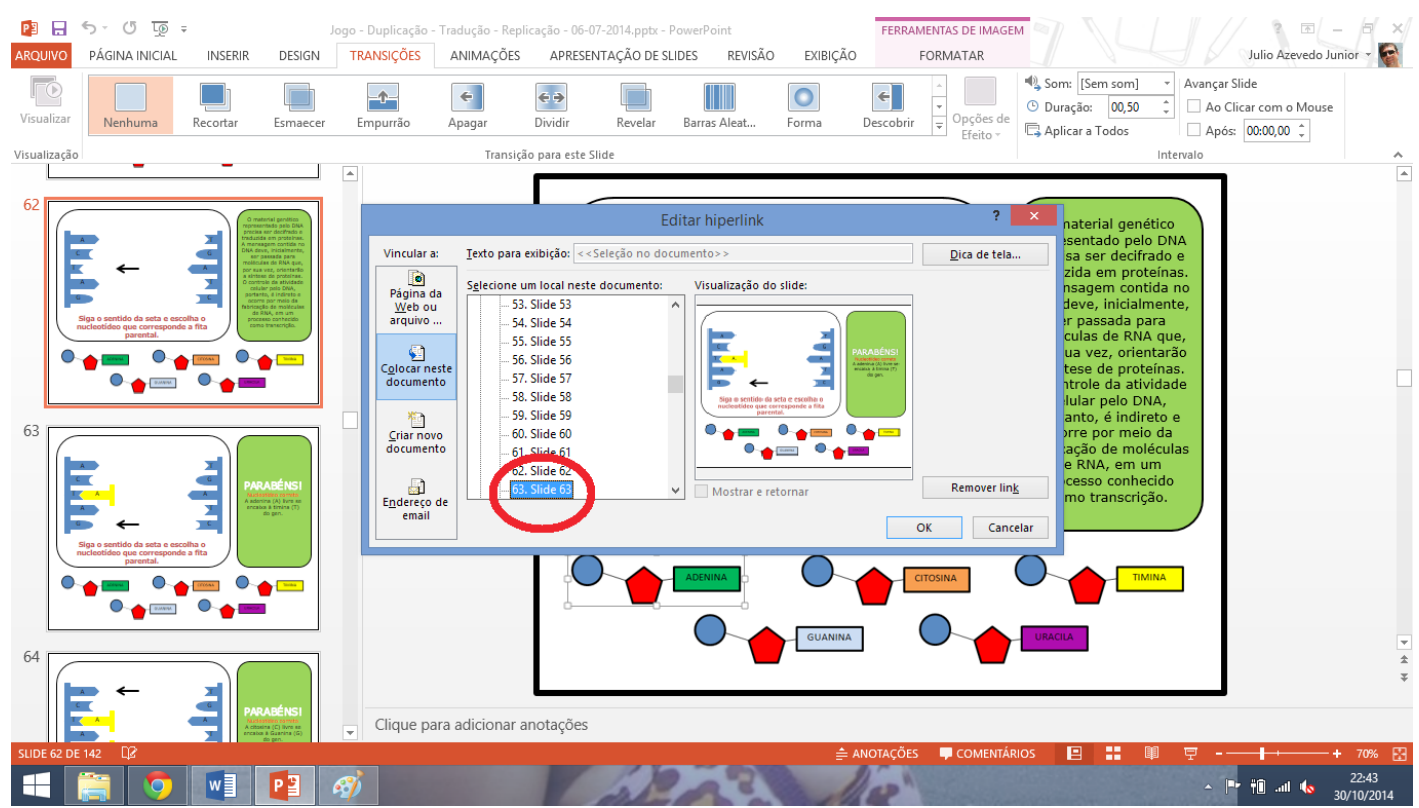

Fonte: ?

Durante a tradução foram adicionadas algumas legendas (Figura 5) para facilitar o entendimento rápido do jogador. As legendas, assim como todos os textos foram adicionados, utilizando o recurso "CAIXA DE TEXTO” (Figura 6). 
Figura 5 - Legendas

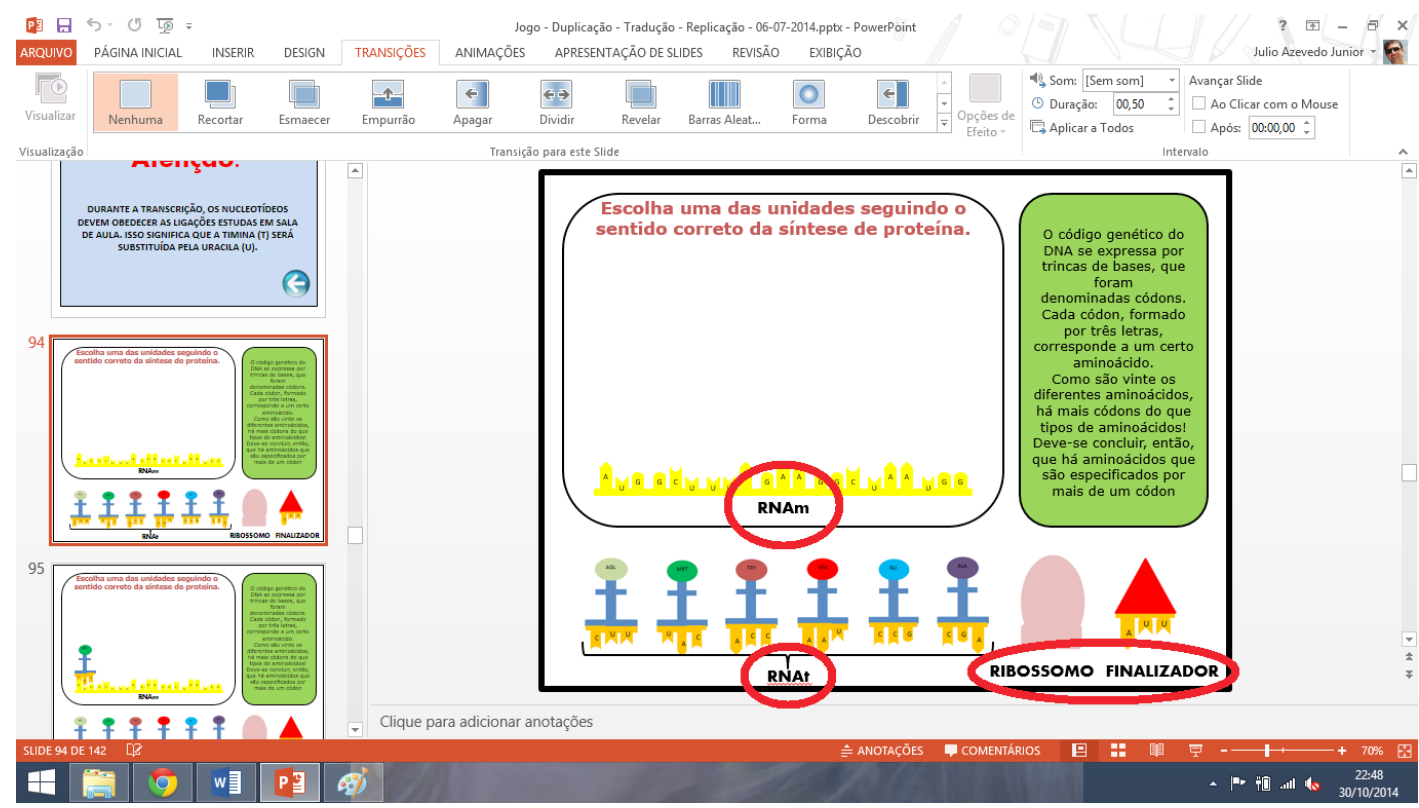

Fonte: ?

Figura 6 - Inserindo Caixa de Texto.

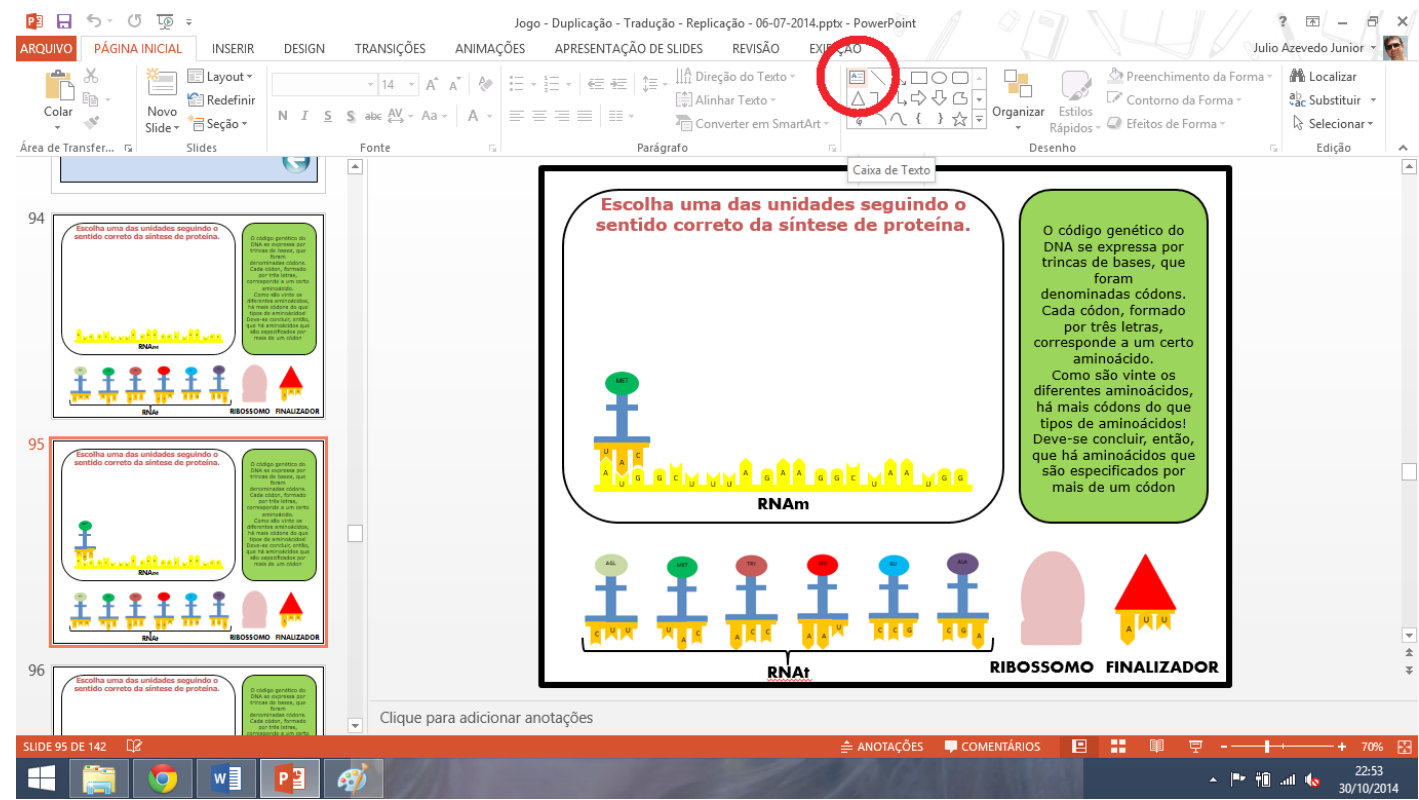

Fonte: ?

\section{PROCEDIMENTOS PARA A UTILIZAÇÃO DO “JOGO DA TRADUÇÃO”: COMO JOGAR?}

É importante ressaltar que o propósito deste jogo é que os mecanismos de duplicação e transcrição e as relações necessárias para ordenar os aminoácidos durante a tradução, possam ser melhor compreendidos. Dessa forma, o objetivo central desta proposta didática é que os alunos possam ter uma melhor compreensão sobre 
qual é a estrutura molecular dos ácidos nucleicos e como ocorre o processo de produção de uma nova proteína, a tradução.

O “Jogo da Tradução” (Figura 7) é um material didático de apoio que pode ser utilizado no ensino médio ou fundamental, apresentando de forma dinâmica e interativa o comportamento das moléculas durante os processos de replicação, transcrição e tradução.

Figura 7 - Jogo da tradução.

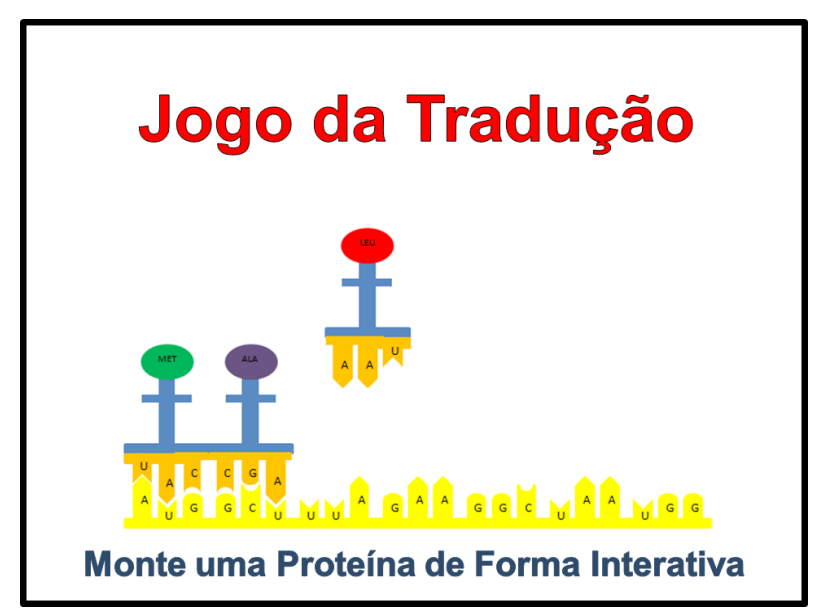

Fonte: ?

O aluno ao utilizar esta ferramenta, tem o controle dos movimentos moleculares, aplicando o conhecimento teórico para construir uma proteína.

A primeira etapa do jogo consiste em uma sequência de slides que representam a replicação de uma molécula de DNA. Após a separação das fitas de DNA (Figura 8), o jogador deve indicar o nucleotídeo correto para a combinação apontada pela seta (Figura 9). Um hiperlink leva o jogador para o slide seguinte, que mostra o nucleotídeo na posição correspondente (Figura10). O objetivo desta etapa é mostrar ao aluno como se constrói duas novas moléculas de DNA, idênticas entre si, método chamado de semiconservativo, unindo os nucleotídeos de acordo com as possíveis ligações após o afastamento das cadeias parentais. 
Figura 8 - Separação das fitas durante a replicação.

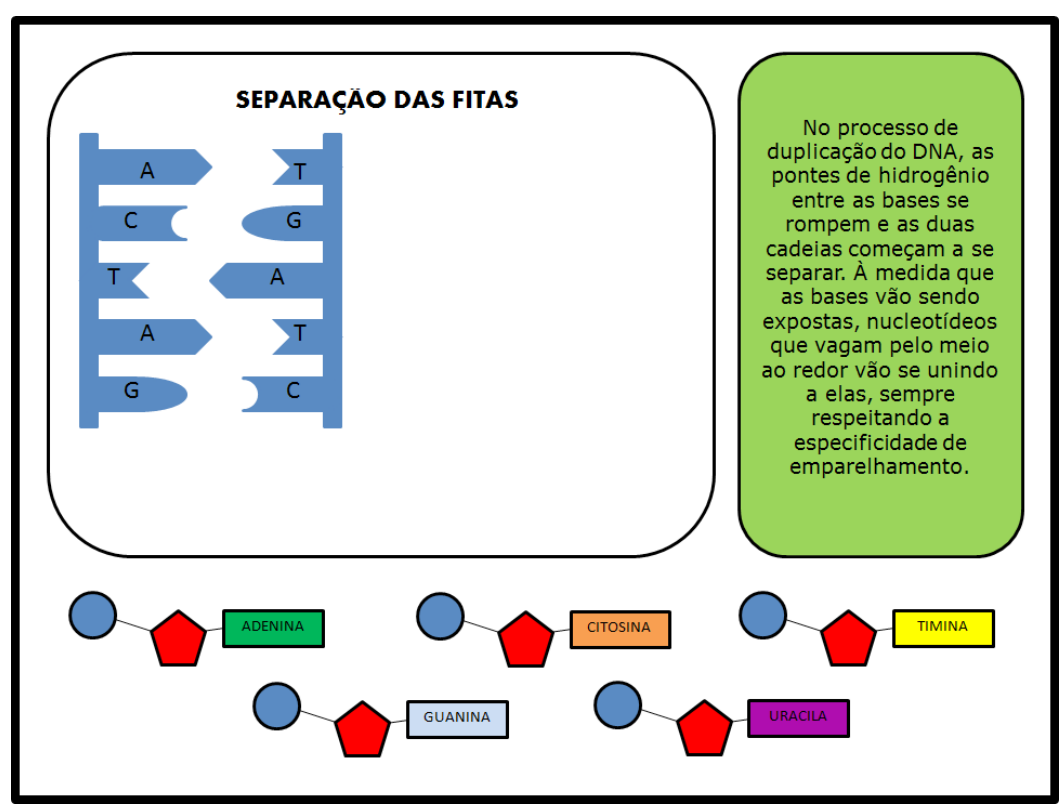

Fonte: ?

Figura 9 - A seta indica a posição do nucleotídeo na replicação.

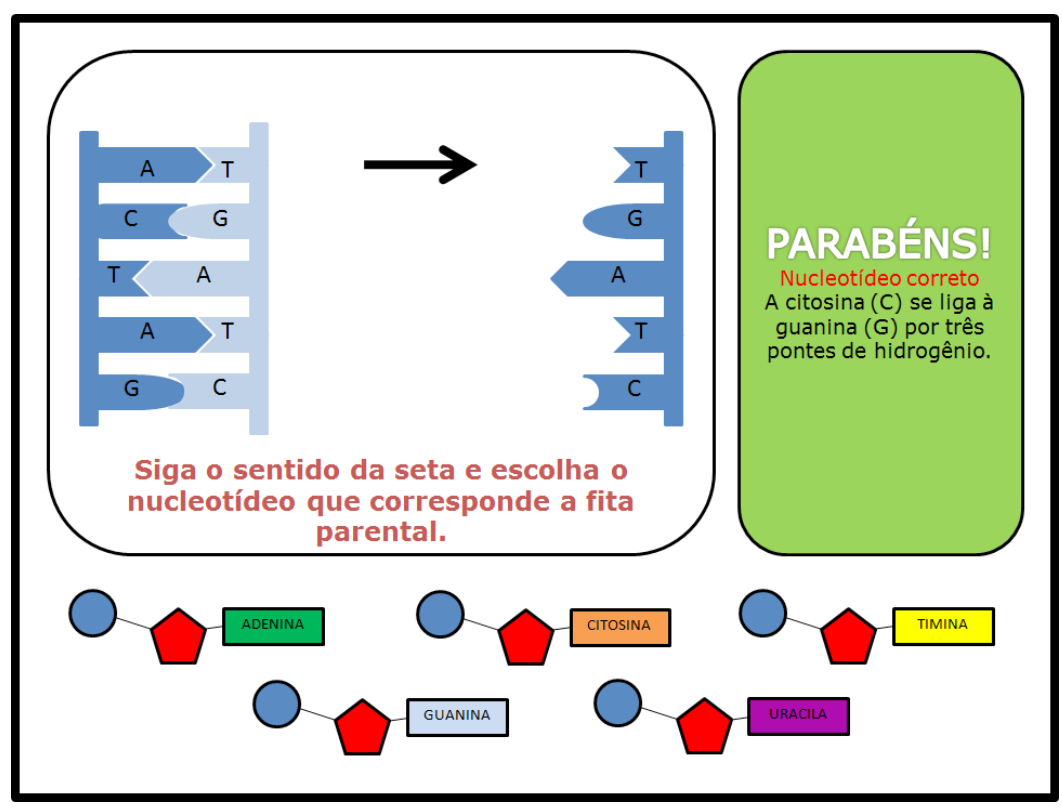

Fonte: ? 
Figura 10 - Um nucleotídeo foi adicionado a posição indicada pela seta.

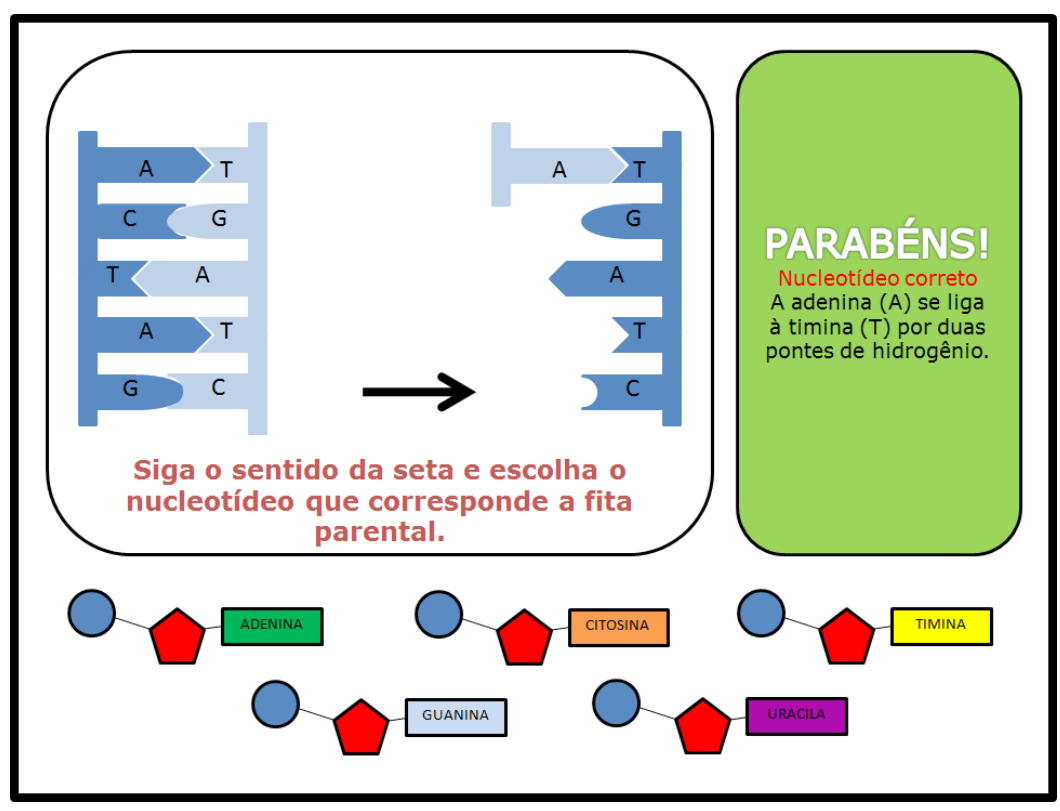

Fonte: ?

A transcrição corresponde à segunda etapa. Agora o jogador deve ficar atento para as combinações entre os nucleotídeos, os hiperlinks foram alterados para que possamos ligar a Uracila no lugar da Adenina, para a construção de uma molécula de RNAm. A seta indica a posição a qual o novo nucleotídeo será inserido (Figura 11). Clicando sobre o ícone correto o slide transita sobre o comando de hiperlink para a próxima tela (Figura 12).

Durante a execução desta segunda etapa, temos o objetivo de mostrar aos alunos, que durante a síntese de uma molécula RNAm, nossas células substituem a timina (T) pela uracila (U), ressaltando também a estrutura de tal molécula, formada uma cadeia simples, diferentemente do DNA que possui cadeia dupla.

Figura 11 - Seta indicando a posição do novo nucleotídeo.

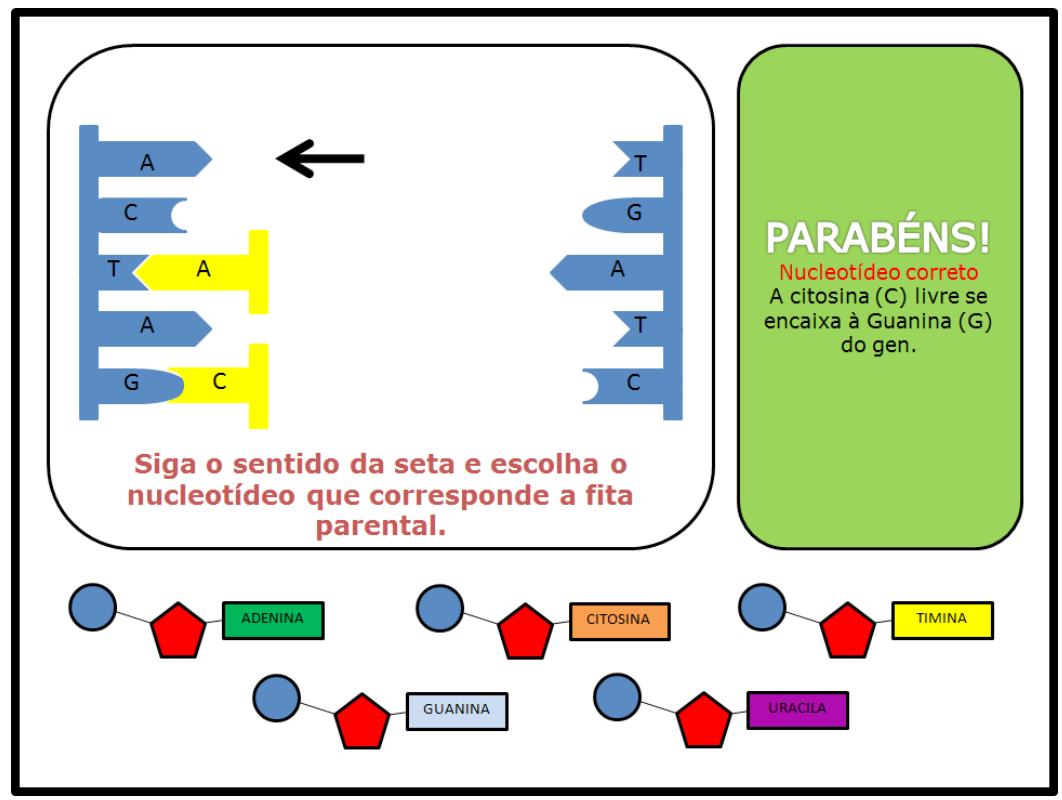

Fonte: ? 
Figura 12 - A Uracila se combina com a Adenina.

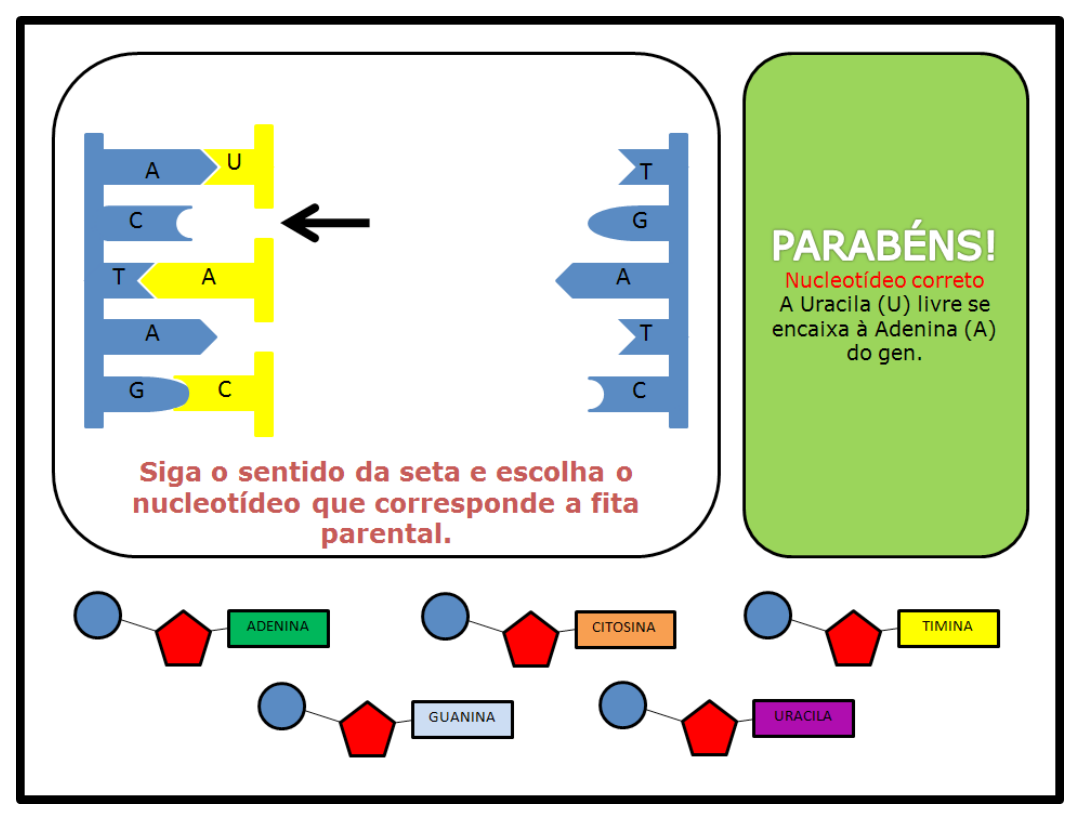

Fonte: ?

A última etapa é a fase da tradução, onde o jogador sintetizará uma proteína com base em uma molécula de RNAm. Agora a tela (Figura 13) é diferente das que aparecem nas etapas anteriores. No lugar dos nucleotídeos adiciona-se moléculas de RNAt ligadas aos respectivos aminoácidos, Ribossomo e um Finalizador.

Assim, obedecendo aos códons do RNA e os Anticódons do RNAt, o jogador clica sobre os ícones seguindo a ordem de tradução. Imediatamente um hiperlink altera o slide colocando a molécula correta em seu devido lugar (Figura 14). Ao indicar o segundo ícone, correspondente ao RNAt correto (Figura 15), torna-se necessário um clique sobre o ribossomo (Figura 16), para que a síntese da ligação peptídica possa ser executada automaticamente pelo jogo. Utilizando a programação de movimento mencionado anteriormente o ribossomo se desloca estabelecendo a ligação entre os dois aminoácidos (Figura 17). Esse mecanismo se repete até a adição do finalizador (Figura 18) onde a proteína é liberada e a tradução concluída (Figura 19).

Nesta última etapa, objetivamos esclarecer os conceitos de códons e anticódons, posicionamento dos aminoácidos para a formação da proteína e a participação do RNAt na formação das ligações peptídicas. O aluno tem a oportunidade de observar como a proteína é montada, mediante a colocação dos aminoácidos em suas devidas posições, o que define a relação de especificidade de cada proteína, que será liberada no interior da célula para ser utilizada posteriormente. 
Figura 13 - Tela inicial da tradução.

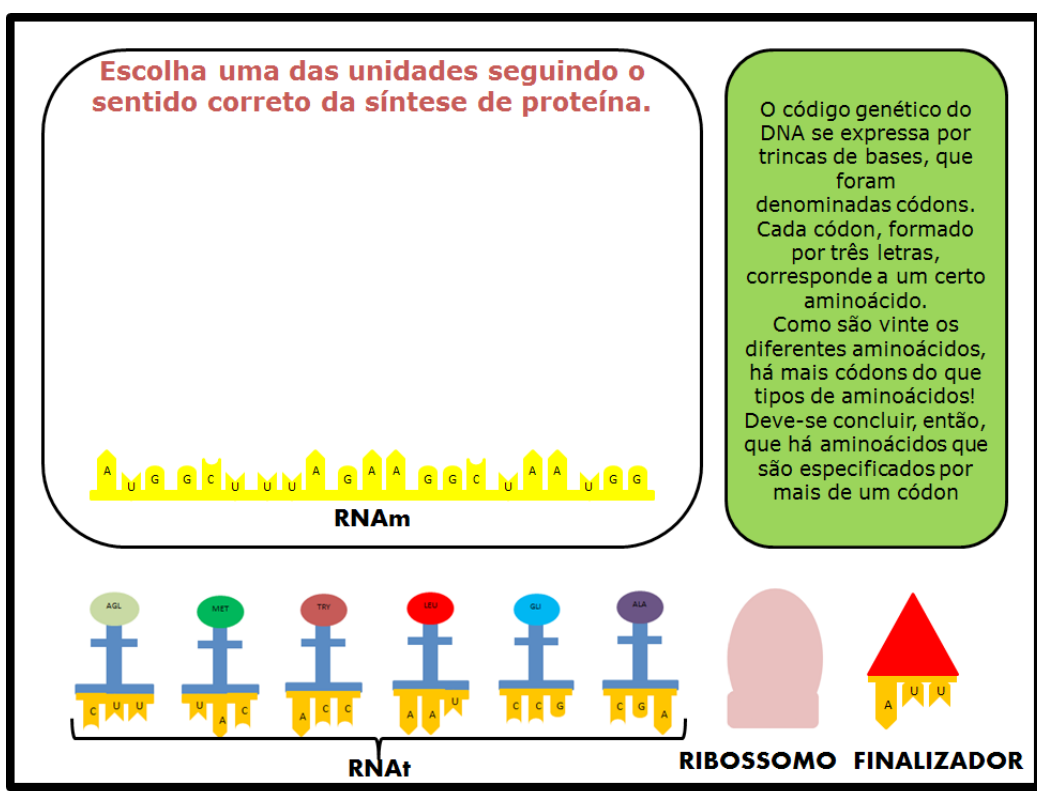

Fonte: ?

Figura 14 - Adição do primeiro RNAt contendo o aminoácido.

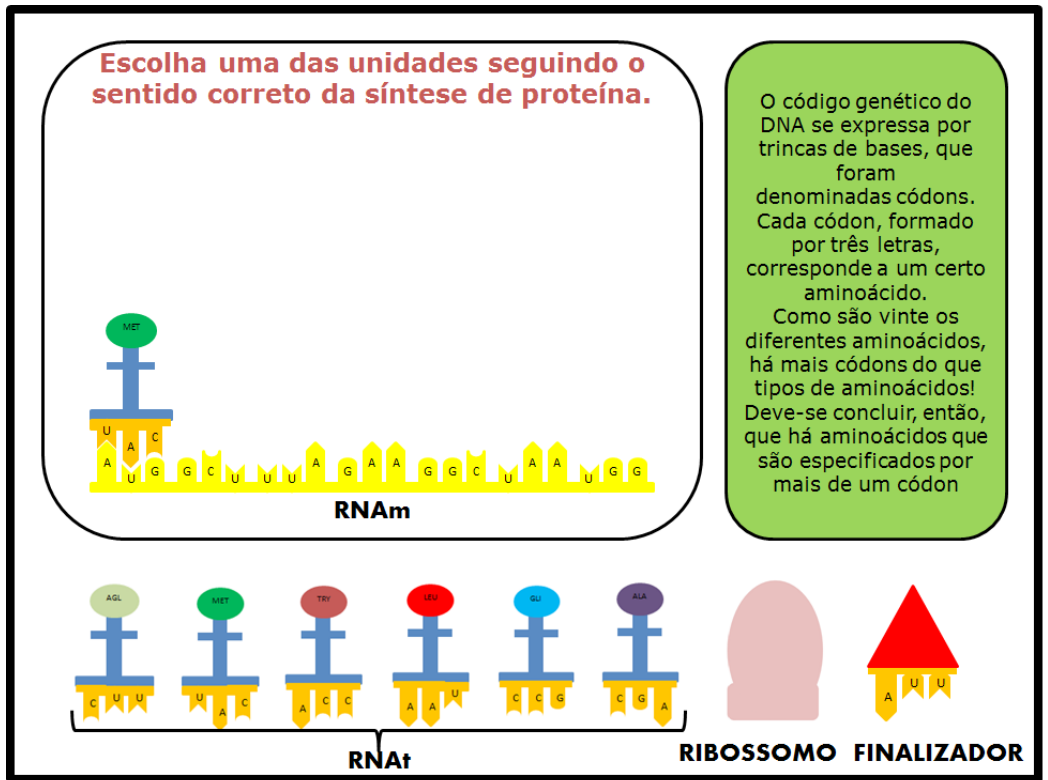

Fonte: ? 
Figura 15 - Adição do segundo RNAt contendo o aminoácido.

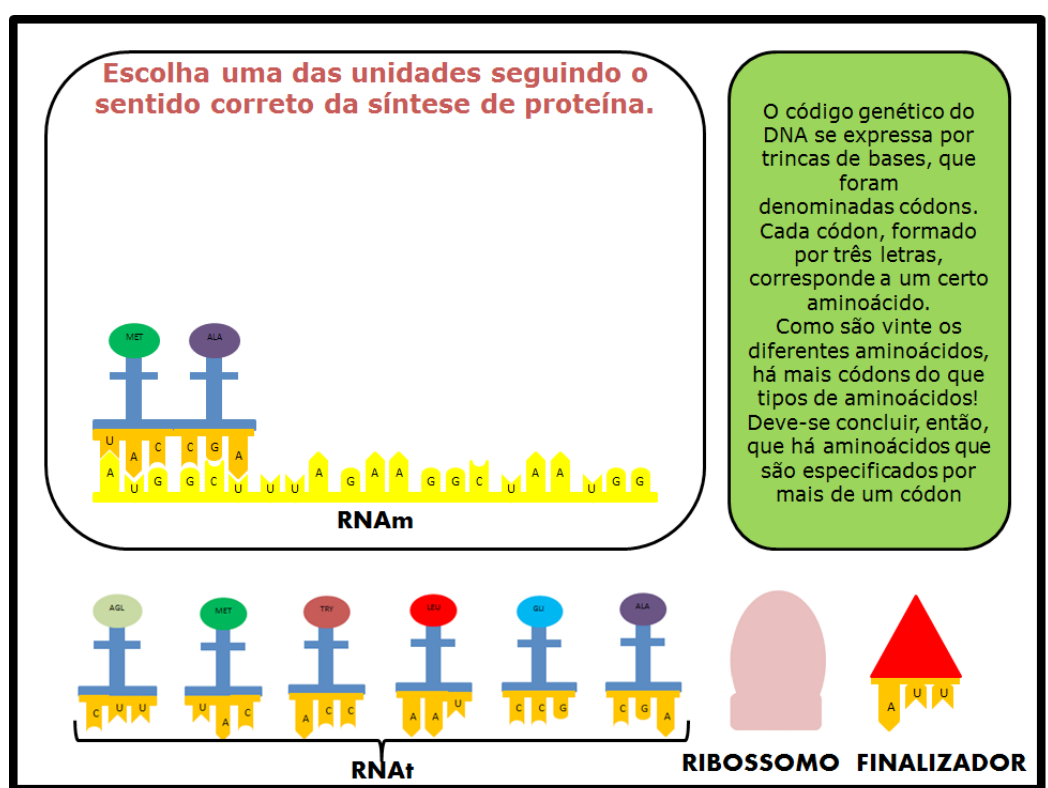

Fonte: ?

Figura 16 - $\mathrm{O}$ ribossomo foi adicionado à tradução.

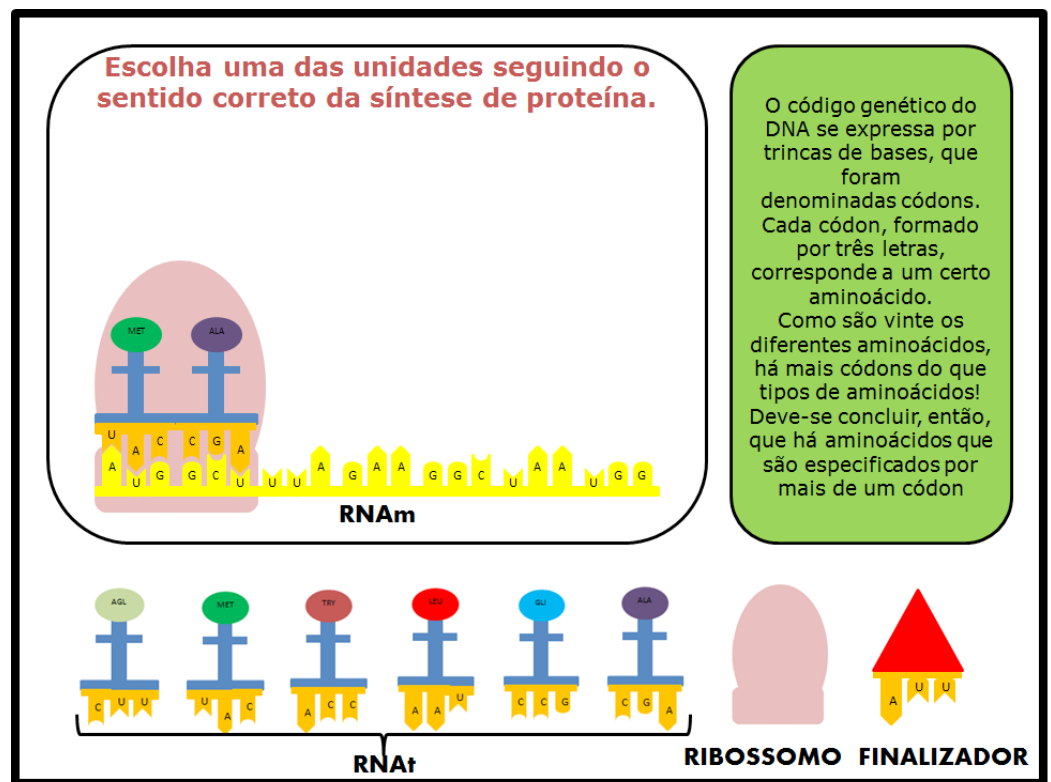

Fonte: ? 
Figura 17 - O ribossomo estabelece a ligação entre os aminoácidos.

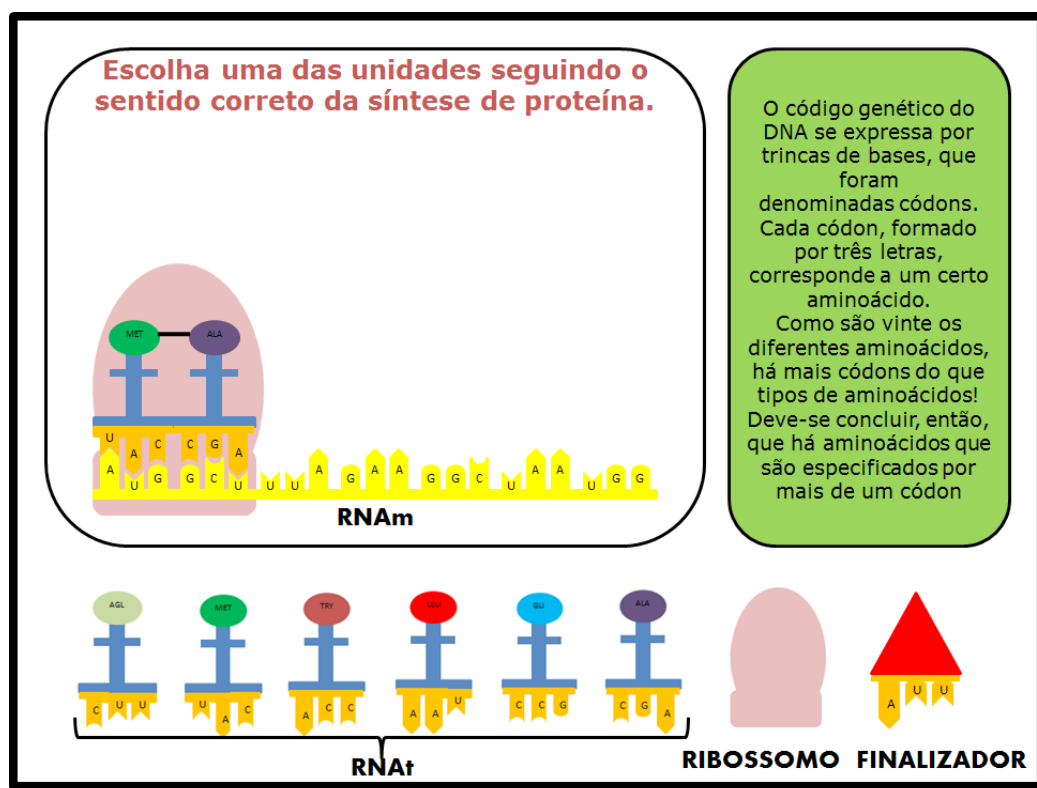

Fonte: ?

Figura 18 - O finalizador foi adicionado junto ao códon de terminação.

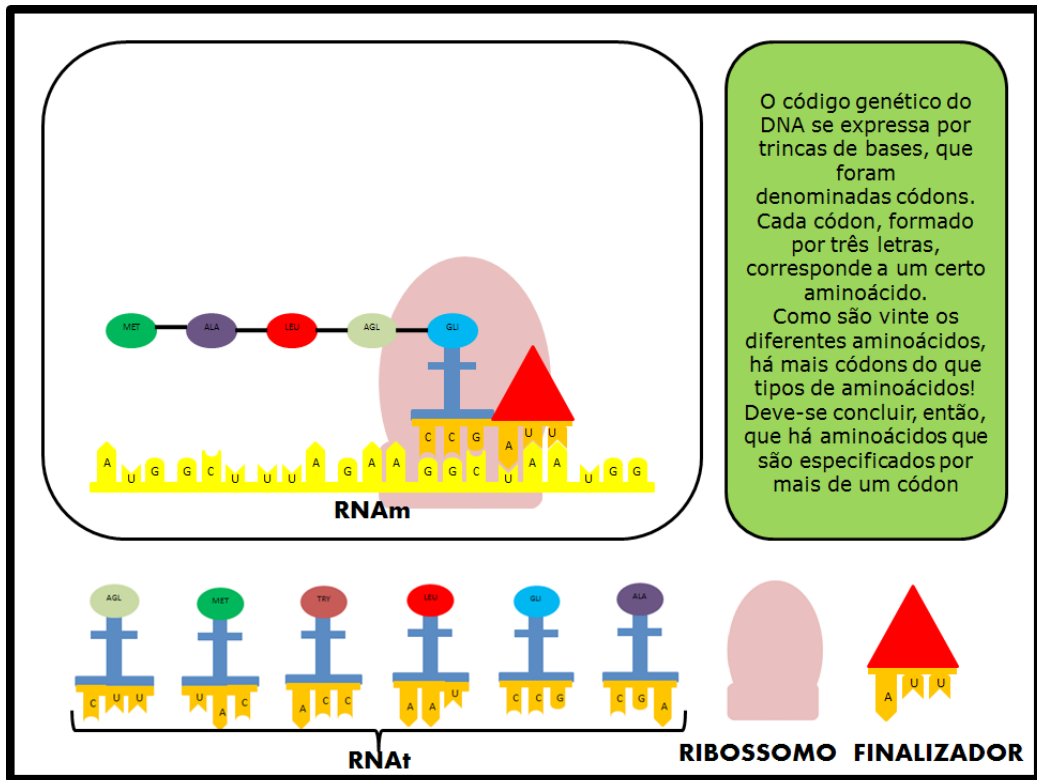

Fonte: ? 
Figura 19 - Conclusão da tradução e liberação da proteína.

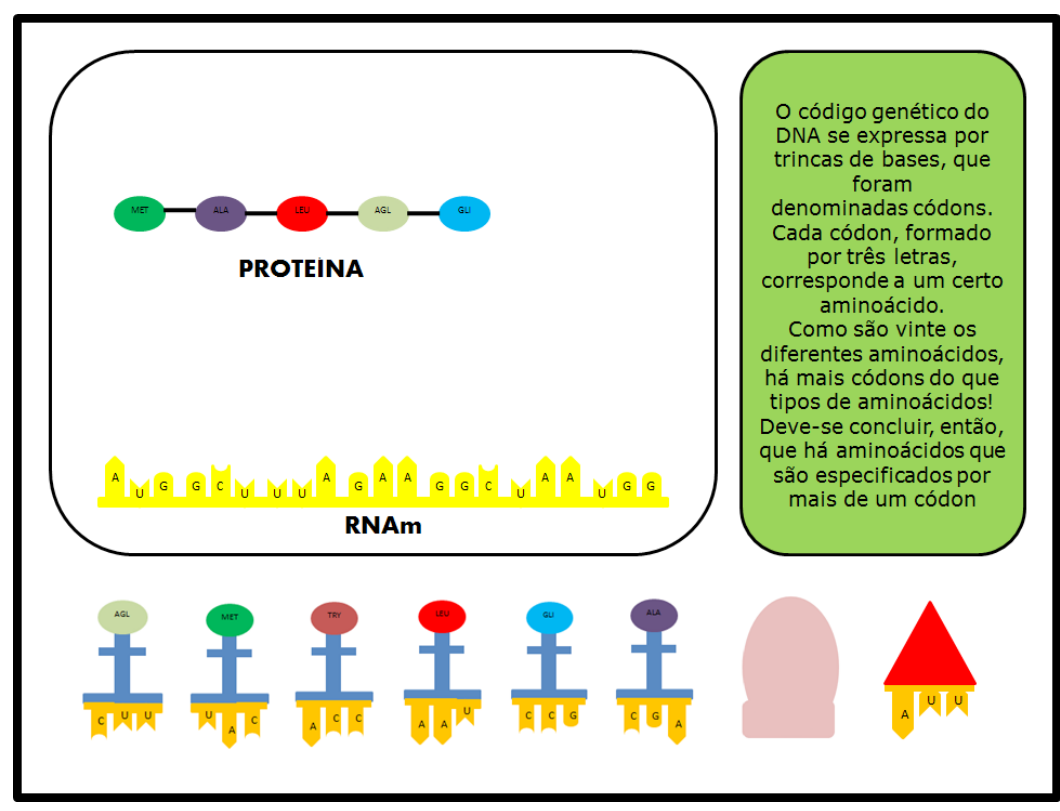

Fonte: ?

\section{INSTRUÇÕES PARA O PROFESSOR}

Inicialmente, o professor deve aplicar o conteúdo teórico (utilizando livros textos, como por exemplo, o de AMABIS \& MARTHO, 2006), considerando que as regras do jogo envolvem os conhecimentos básicos sobre genética molecular. As combinações possíveis entre os nucleotídeos durante a replicação e transcrição, a substituição da timina pela uracila durante a síntese de RNAm, a formação de códons e sua combinação com os anticódons para o posicionamento do aminoácido e a função do ribossomo em todo o processo de fabricação da proteína são exemplos do que o aluno precisa saber para concluir bem a utilização do jogo.

Antecipadamente o professor deve verificar, se existe um laboratório de informática na escola e a quantidade de alunos que o mesmo comporta, buscando colocar no máximo uma dupla por computador.

Após a organização da turma o professor orienta os alunos a baixarem o jogo e iniciarem a atividade seguindo os princípios citados anteriormente.

\section{HOSPEDAGEM DO “JOGO DA TRADUÇÃO”}

Aqui é apresentada a página onde se pode encontrar o “Jogo da Tradução” pronto para ser utilizado.

Entrando na página http://www.unifoa.edu.br/divulgacao-cientifica/projetos basta clicar sobre o ícone "Projeto completo", e baixar o jogo.

\section{CONSIDERAÇÃO FINAL SOBRE O “JOGO DA TRADUÇÃO”}

O “Jogo da Tradução” possibilita a observação de forma lúdica e interativa do metabolismo e dos movimentos exercidos pelas moléculas durante a construção das novas fitas de DNA, fabricação do RNAm e síntese de proteína. 
Além disso o jogo permite o professor trabalhar de forma lúdica, interativa e contextualizada o conteúdo de genética molecular, um assunto normalmente tratado de forma exclusivamente teórica. Com a combinação dessa teoria e artifícios de informática, o aluno que cada vez mais transita pelo ambiente digital, pode manifestar um maior interesse à disciplina e, consequentemente, apresentar maior estímulo ao aprendizado desses temas.

As tecnologias, se utilizadas por profissionais que compreendam sua relevância no processo de ensino e aprendizado, podem configurar-se em importante estratégia educacional, uma vez que permitem uma interação com o aluno tanto no sentido de apresentar-lhes diferentes conteúdos, quanto na possibilidade de que o aprendiz e professor possam interagir possibilitando a construção de um novo conhecimento.

\section{REFERÊNCIAS}

AMABIS J. M.; MARTHO, G. R. Fundamentos da Biologia Moderna. 4ª edição. São Paulo: Editora Moderna, 2006.

BAHAR, M.; JOHNSTONE, H.; H, M.H. Revisiting learning difficulties in biology. Journal Biology Education, v. 33, n 2, 1999.

BANET, E., AYUSO, G. E. Introduccion a la genética em la ensenanza secundaria y bachillerato. Ensenanza de las Ciências, v. 13, n. 2, p. 137-153, 1995.

BUGALLO. La Didática de la Genética: revisión bibliográfica. Enseñanza de las Ciências, v. 13, n. 3, p. 379385, 1995.

CHEN, M. M.; SCOTT, M. S. STEVENS, D. J. Technology as a tool in teaching quantitative biology at the secondary and undergraduate levels: a review. Letters in Biomathematics. v. 5, n. 1, p. 30-48, 2017.

CHIFWA, J. The teaching of genetics in selected secondary schools in Kitwe District, Zambia. $2015.143 \mathrm{f}$. Dissertação (Mestrado em Educação e Ciência da Educação). Universidade da Zambia, Lusaka.

FESTAS, M. I. A aprendizagem contextualizada: análise dos seus fundamentos e práticas pedagógicas. Educ. Pesqui. v. 41, n. 3, p. 713-728, jul/set. 2015.

FLEISCHNER, T. L. et. al. Teaching Biology in the Field: Importance, Challenges, and Solutions. BioScience. v. 67, n. 6, p. 558-567, 2017.

Haambokoma C., B., et. al. Strengthening of Mathematics and Science Education in Zambian Secondary Schools. Baseline Study Report. Lusaka: Ministry of Education and Japan International Co-operation Agency. 2002.

MACEDO, C. C.; SILVA, F. L. Os Processos de Contextualização e a Formação Inicial de Professores de Física. Investigações em Ensino de Ciências. v. 19, n. 1, p. 55-75, 2014.

MIRRA, N. From Connected Learning to Connected Teaching: Edtitor's Introdution. Citejournal. v. 18, n. 2, p. 1-5, 2018.

SAFITRI, M. et al. Integration of Various Technologies in Biology Learning. Journal of Physics: Conf, Series 895 p. 1-4, 2017. 